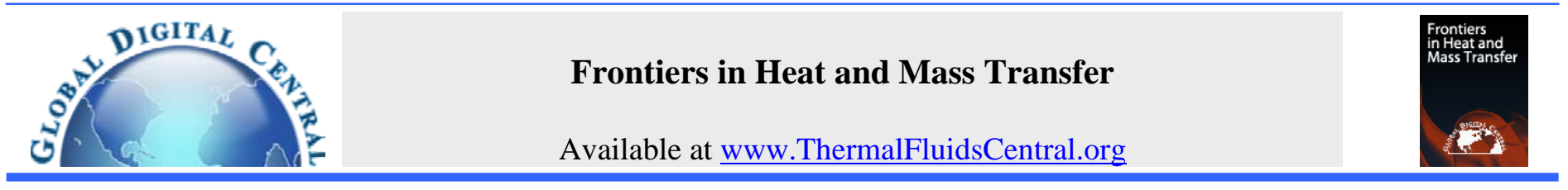

\title{
PRESSURE DROP MEASUREMENTS WITH BOILING IN DIVERGING MICROCHANNEL
}

\author{
Amit Agrawal, ${ }^{\mathrm{a}, *}$, V.S. Duryodhan ${ }^{\mathrm{a}}$, S. G. Singh ${ }^{\mathrm{b},}$ \\ ${ }^{a}$ Department of Mechanical Engineering, Indian Institute of Technology Bombay, Powai, Mumbai, 400076, India. \\ ${ }^{\mathrm{b}}$ Department of Electrical Engineering, Indian Institute of Technology, Hyderabad, 502205, India
}

\begin{abstract}
An experimental study of flow boiling through diverging microchannels has been carried out in this work, with the aim of exploring reduction in flow instabilities during boiling in diverging microchannels. Effect of mass flux, heat flux and divergence angle on two phase pressure drop has been studied using deionized water as the working fluid. The experiments are carried out on three test sections with divergence angle of 4 , 8 and 12 deg with nearly constant hydraulic diameter (146, 154 and $157 \mu \mathrm{m}$ respectively), for inlet mass flux and heat flux range of $117-1197 \mathrm{~kg} / \mathrm{m}^{2}$-s and 2.5 to $19.7 \mathrm{~W} / \mathrm{cm}^{2}$ respectively. Pressure drop with respect to mass flux is linear and non-linear in single and two phase regimes, respectively. There are up to three points in single/two-phase regime having the same pressure drop, which is similar to uniform cross section microchannel. However, unlike uniform cross section microchannel, the slope of demand curve at the point of onset of flow boiling is less steep in diverging microchannel; further, the slope is an inverse function of the divergence angle. Preliminary study suggests that diverging microchannel can reduce the flow instabilities.
\end{abstract}

Keywords: divergence angle, instabilities, two-phase regimes

\section{INTRODUCTION}

The transistor was invented in 1948 and today integrated circuit has a size of $45 \mathrm{~nm}$ (gate length) in production and approaches $22 \mathrm{~nm}$ in research laboratories. Microelectronics devices, which include a variety of applications such as personal computers, servers, laser diodes, and RF devices are pushing the heat flux density requirements to higher levels. Singh et al. (2009a, 2011) for the first time performed in situ impact analysis of very high heat flux transients on the characteristics of RTD, p-n diode and MOSFET. The authors showed that the p-n diode power exponent factor is highly sensitive to transient heat flux conditions. Singh et al. (2011) reported that the rate of mitigation in MOSFET operation is higher at lower flow rates because of the higher heat transfer efficiency of two phase flow. They also proposed a technique for localizing hotspots by utilizing an on-chip distributed RTD sensor array. These advances have allowed dissipation of about $200 \mathrm{~W} / \mathrm{cm}^{2}$ of heat. The new challenge for the coming decade is mitigating heat flux on the order of $600-1000 \mathrm{~W} / \mathrm{cm}^{2}$. Such high level of heat dissipation requires a dramatic reduction in the cooling channel dimensions so that a higher surface area to volume ratio can be achieved; the latent heat of the working fluid needs to be further utilized for dissipating the heat.

Kennedy et al. (2000) experimentally studied the onset of nucleate boiling (ONB) and onset of flow instability (OFI) in uniformly heated microchannels of inner diameter $1.45 \mathrm{~mm}$ with subcooled water flow. They generated demand curves (pressure drop versus flow rate curve) and utilized these for the specification of the ONB and OFI points. They observed that the instability sets in at a slightly lower mass flux than the onset of significant void condition. Kandlikar et al. (2002) studied flow boiling of water in electrically heated multichannel evaporators consisting of six parallel microchannels. They used a 1000 frames per second camera to visualize the ensuing flow patterns (bubbly, slug, and annular). Further, nucleation was observed in the bulk fluid as well as in the liquid film. The visual confirmation of flow reversal in some of the microchannels was also obtained from their experiments. Singh et al. (2009b) observed the different flow regimes (bubbly, slug and annular) with boiling water in a microchannel of hydraulic diameter $140 \mu \mathrm{m}$. They developed a novel image analysis method to determine the void fraction and frequency of occurrence of different regimes, and presented a unique flow regime map. Qu and Mudawar (2003) studied two-phase pressure drop of water flowing in 21 parallel copper microchannels heat sink, each having a cross section of $231 \times 713 \mu^{2}$. They found that two types of two-phase hydrodynamic instability occur during flow boiling (severe pressure drop oscillation and mild parallel channel instability) and speculated the possibility of reversed flow. In their subsequent work $(\mathrm{Qu}$ and Mudawar 2004), they observed backflow of vapor from the microchannels into the inlet plenum as CHF was approached. Wu and Cheng (2006) carried out simultaneous visualization and measurements to study pressure drop and flow instabilities at various mass fluxes and heat fluxes during flow boiling of deionised water in a $60 \mathrm{~mm}$ long, eight parallel microchannels, each of hydraulic diameter $72.7 \mu \mathrm{m}$ etched on silicon. They observed occurrence of ONB and OFI in their microchannels which depend on both mass flux and heat flux. With increase of heat flux, OFI moved towards the direction of larger mass flux, and at the same time, the difference in mass fluxes between ONB and OFI decreased. Kandlikar and Balasubramanian (2005) visualized the water flow through a microchannel of hydraulic diameter $333 \mu \mathrm{m}$ at different mass flux, heat flux and microchannel locations using a high speed camera. Channel dryout and rewetting were observed periodically. They also observed reversed flow liquid-vapor interfaces in a few microchannels. They further suggested that the onset of nucleate boiling introduces a pressure spike at the nucleation location as

*Corresponding author, Email: amit.agrawal@iitb.ac.in 
shown qualitatively by Kandlikar (2006). This pressure spike can be stabilized by introducing a pressure drop element, in addition to artificial nucleation sites, and by operating the system with an inlet pressure above the pressure spike. Singh et al. (2008) studied the impact of aspect ratio on flow boiling of water in different rectangular microchannels of same hydraulic diameter of $142 \mu \mathrm{m}$ and length of 20 $\mathrm{mm}$. They observed experimentally that the minimum pressure drop across the rectangular microchannel occurs at an aspect ratio of about 1.56. Furthermore, they suggested that annular flow model is good for approximately square cross-sections but poor for large aspect ratio rectangular cross-section microchannels. Yen et al. (2006) studied convective boiling of HCFC-123 in transparent microchannels of same hydraulic diameter of $214 \mu \mathrm{m}$ but different cross-sections. They observed that the heat transfer coefficient was higher for square microchannel (because of corners which acted as active nucleation sites) as compared to circular shaped microchannel. Lee et al. (2004) and $\mathrm{Li}$ et al. (2004) experimentally investigated bubble dynamics in a single microchannel having a hydraulic diameter of $41.3 \mu \mathrm{m}$ and two parallel microchannels with a hydraulic diameter of $47.7 \mu \mathrm{m}$, respectively using DI water as working fluid. It was observed that the reversed flow occurred more easily in parallel microchannels than in a single microchannel, and also at low mass flux and high heat flux values.

Studies carried out by various research groups on flow boiling in uniform cross section microchannel have suggested that two phase flow instability is of great concern. Flow instability could lead to lowering the values of the critical heat flux (CHF), resulting in damage to the microelectronics chip and can therefore lead to serious performance issues. Bergles and Kandlikar (2005) argued that the CHF get affected by flow oscillation. Kuo and Peles (2008) quoted that Flow instabilities in microchannels not only cause an uneven thermal stress on the heating surface, but also lead to an early appearance of critical heat flux (CHF). Park et al. (2009) in their work on effect of inlet orifice on saturated CHF shows that, flow easily get subjected to instability and caused CHF to occur at much lower values than occurred with the orifices in place. Various groups have therefore been making efforts to reduce the flow instability during boiling in microchannels. Whereas some workers tried inserting throttling devices at the inlet, others have worked with different shapes and sizes of microchannels. For example, Wang et al. (2008) studied flow boiling instabilities water as working fluid in parallel microchannels in presence of external flow resistors, as suggested by Qu and Mudawar (2003). Using different inlet and outlet configurations they found out that the microchannel in which flow enters through the restriction and exits freely exhibits much less flow instabilities. Lee and Pan (2008) studied and compared the boiling heat transfer and two phase flow of water in a single shallow uniform crosssection microchannel $\left(h=20 \mu \mathrm{m}, D_{h}=33.3 \mu \mathrm{m}\right)$ and a diverging microchannel ( $\left.h=20 \mu \mathrm{m}, D_{h}=33.3 \mu \mathrm{m}\right)$ with a small divergence angle of $0.183 \mathrm{deg}$. They noted that for the same mass flow rate, the diverging microchannel shows a higher single phase flow pressure drop, while the two phase pressure drop is approximately the same. Bhide et al. (2011) studied the effect of external pulsations on flow boiling. They observed that the pressure fluctuation reduce significantly at high frequency of external pulsation; also the average pressure was found to reduce for certain cases. They proposed that the presence of annular flow regime at high frequency imparts stability to the flow. See Agrawal and Singh (2011) for a comprehensive and up-to-date review on flow boiling in microchannel.

In the present work, an experimental study has been carried out on two phase boiling flow through diverging microchannels. The effect of flow rate, heat flux and divergence angle on the mean pressure drop and pressure/ temperature instabilities have been studied. The result has been compared qualitatively with the corresponding results for uniform cross-section microchannel from the literature. Similar to single phase flow through a diverging microchannel, any existence of critical angle for two-phase boiling flow has also been explored in this work.

\section{EXPERIMENTAL SETUP}

Schematic of the experimental setup employed in the measurements is shown in Fig. 1, which is similar to that employed earlier by Singh et al. (2008, 2009c). It consists of deionized water reservoir, pump, damper (to remove pressure fluctuations in the incoming stream), differential pressure gauge, test section, DC power supply, data logger for inlet/ outlet temperature recording, and a high speed camera. All devices are connected using silicone tubing (Master Flex). A pre-calibrated peristaltic pump (Master Flex) is used for metering and controlling the mass flow rate of water. A pre-calibrated digital pressure gauge (Keller) with a response time of $1 \mathrm{~s}$ and range of -1 to 3 bars is used to measure the pressure across the microchannel. A contact probe is used to make electric contact between microheater and power source meter. K-type thermocouples are placed inside the inlet and outlet reservoir and connected to data logger to measure temperature.

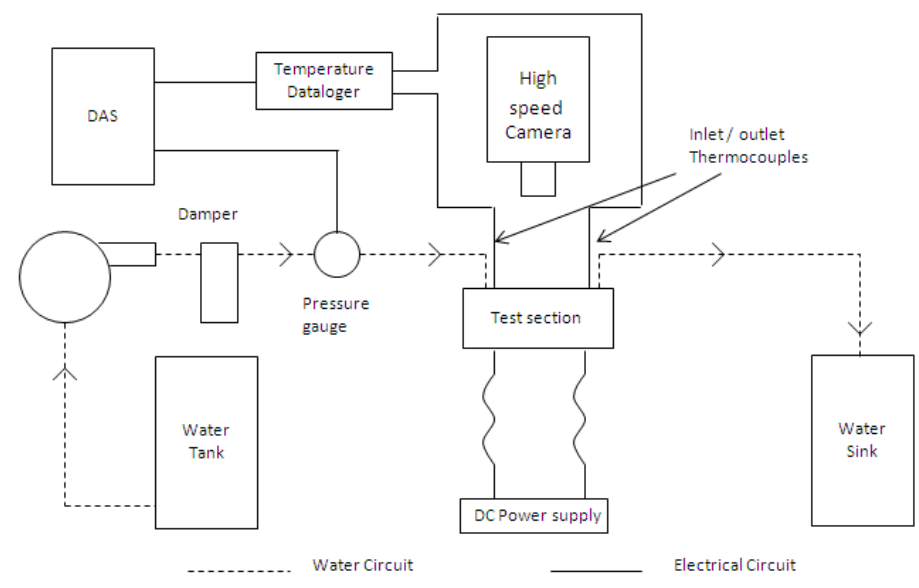

Fig. 1 Schematic of experimental set-up.

All test sections are fabricated using in-house micro-fabrication facility. Single-sided polished, (100) p-type, 2" silicon wafer with resistivity $0.002-0.005 \Omega$ is used for fabrication. The fabrication process (given in Singh et al. 2008) can be divided into RCA cleaning, wet oxidation, photolithography, TMAH etching and bonding. Photolithography is the conventional fabrication technique used to transfer the pattern from hard mask to soft mask over an oxidized wafer. Silicone oxide acts as the soft mask for TMAH etching where precise control of the process parameters decides the surface roughness. Characterization of etched microchannel is done on a profilometer, where microchannel depth and surface roughness are determined. The surface roughness of all the microchannels is less than $0.1 \mu \mathrm{m}$. Wafer bonding with quartz plate is an important step as it decides the maximum pressure up to which the test section can work without leakage.

Detailed geometrical specifications of the microchannels employed in the experiments are given in Table 1. Three microchannels of different divergence angle but same hydraulic diameter were fabricated. The variation in hydraulic diameter, caused primarily due to the uncertainty involved in the wet etching process, is within $\pm 4 \%$. The hydraulic diameters in Tables 1 are calculated using the mean value of inlet and outlet widths, i.e. at the midpoint of the microchannel. The length of all test sections is maintained constant at $20 \mathrm{~mm}$. The dimensions of the reservoirs at the two ends are $7 \mathrm{~mm} \times 7 \mathrm{~mm}$ in size, with depth equal to the microchannel depth.

The pressure gauge reading gives the pressure drop in test section including the losses inside the connecting tubes, fittings, and entry/exit. The pressure drop across the tubing without the microchannel is also measured; this reading was validated against theory over the entire range of flow rate $(0.1$ to $1.0 \mathrm{ml} / \mathrm{min})$. The net pressure drop across the test section has been obtained by subtracting the pipe losses. K-type 
thermocouples with response time of $1 \mathrm{~s}$ were placed in the inlet and outlet reservoirs close to the inlet and outlet points of the microchannel to measure the temperatures of incoming and outgoing fluid.

Table 1 Geometrical specification of microchannels of different divergence angle with approximately constant hydraulic diameter.

\begin{tabular}{|l|c|c|c|c|c|}
\hline \multicolumn{1}{|c|}{ Microchannel } & I st & II nd & III rd & $\begin{array}{c}\text { Uncer- } \\
\text { tainty }\end{array}$ & Unit \\
\hline $\begin{array}{l}\text { Inlet top width } \\
\left(\mathrm{W}_{\mathrm{t}(\mathrm{i})}\right)\end{array}$ & 231 & 231 & 229 & \pm 2 & $\mu \mathrm{m}$ \\
\hline $\begin{array}{l}\text { Outlet top } \\
\left.\text { width (W } \mathrm{W}_{\mathrm{t}(\mathrm{o})}\right)\end{array}$ & 4431 & 3028 & 1629 & \pm 2 & $\mu \mathrm{m}$ \\
\hline Length (L) & 20000 & 20000 & 20000 & \pm 0.1 & $\mathrm{~mm}$ \\
\hline Height $(\mathrm{H})$ & 82 & 82 & 81 & \pm 1.0 & $\mu \mathrm{m}$ \\
\hline $\begin{array}{l}\text { Divergence } \\
\text { Angle }(\theta)\end{array}$ & 12 & 8 & 4 & \pm 0.25 & $\mathrm{deg}$ \\
\hline $\begin{array}{l}\text { Hydraulic } \\
\text { Diameter }\left(\mathrm{D}_{\mathrm{h}}\right)\end{array}$ & 157 & 154 & 146 & \pm 1.64 & $\mu \mathrm{m}$ \\
\hline
\end{tabular}

The following procedure was followed while performing the experiments. Deionized water was vigorously boiled for $30 \mathrm{~min}$ to remove dissolved air and then cooled to the ambient temperature of $25^{\circ}$ C. The flow was started and then an input electric power was provided by supplying a fixed voltage and current using a power sourcemeter. Continuous monitoring of the inlet and outlet temperatures and pressure drop were done to check for steady state. Once steady state condition is achieved, all relevant parameters such as pressure drop, inlet-outlet temperatures, supplied power and flow rate are recorded as a function of time. The above procedure is repeated for the entire range of flow rates. The experimental uncertainties encountered are listed in Table 2.

Table 2 Estimation of error in various parameters measured.

\begin{tabular}{|c|c|}
\hline Parameter & Maximum Error \\
\hline$\dot{m}$ & $0.01 \mathrm{ml} / \mathrm{min}$ \\
\hline$\Delta \mathrm{P}$ & $2 \mathrm{mbar}$ \\
\hline $\mathrm{T}$ & $0.5^{\circ} \mathrm{C}$ \\
\hline Electrical power supplied & $0.03 \mathrm{~W}$ \\
\hline $\mathrm{D}_{\mathrm{h}}$ & $1.12 \%$ \\
\hline
\end{tabular}

\section{EFFECT OF MASS FLOW RATE AND HEAT FLUX ON PRESSURE DROP}

Experiments presented in this section were carried out on a microchannel with a divergence angle of 4 deg in the flow rate range of 0.1 to $1 \mathrm{ml} / \mathrm{min}$ (inlet mass flux of $120-1197 \mathrm{~kg} / \mathrm{m}^{2}-\mathrm{s}$ ) and heat flux range of 2.5 to $19.7 \mathrm{~W} / \mathrm{cm}^{2}$.

\subsection{Effect of Mass flow rate}

Figure 2(a) shows the variation of pressure drop with mass flux at a fixed heat flux of $13.5 \mathrm{~W} / \mathrm{cm}^{2}$. The corresponding variation when no heat flux is supplied to the microchannel (i.e. experimental pressure drop for single phase) is also plotted in the figure for comparison.
Notice that the curve corresponding to no heating is linear, as expected because the pressure force and the viscous force are balancing each other; whereas the other curve is non-linear. This linear behaviour is also confirmed from $f \cdot R e$ versus Re plot as shown in Fig. 2(b), where calculated fRe values average around the theoretical value obtained using Morini's correlation (Morini, 2004). The flow is in single phase from 1197 to $838 \mathrm{~kg} / \mathrm{m}^{2}$-s even when heating is applied. Owing to reduction in fluid viscosity due to an increase in temperature (because of heating) the single-phase pressure drop is lower than the corresponding pressure drop value without heating.

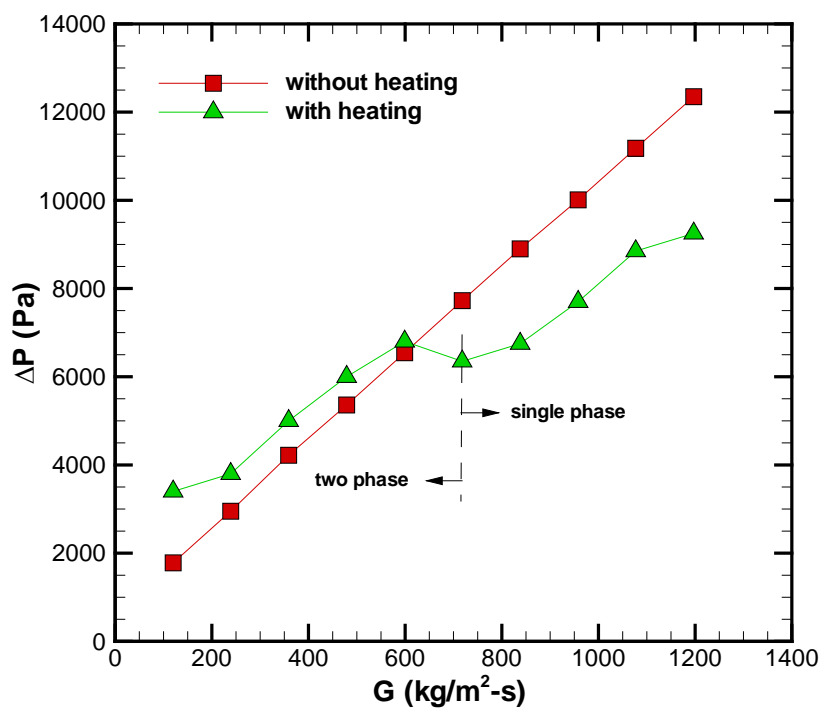

(a)

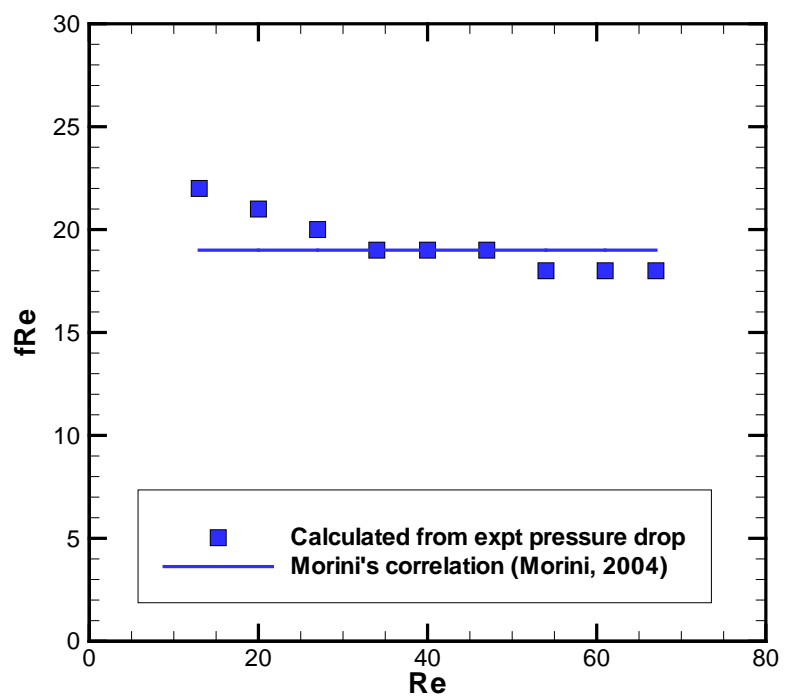

(b)

Fig. 2 (a) Single phase and two phase variation in pressure drop with mass flux inside 4 deg microchannel. The heat flux is 0 and 13.5 $\mathrm{W} / \mathrm{cm}^{2}$, respectively, for the two cases. (b) $f \cdot \operatorname{Re}$ versus Re for flow through 4 deg microchannel without heating.

Boiling initiates at $718 \mathrm{~kg} / \mathrm{m}^{2}$-s and progress towards $120 \mathrm{~kg} / \mathrm{m}^{2}$-s. Boiling happening at $718 \mathrm{~kg} / \mathrm{m}^{2}$-s is entirely sub-cooled boiling as indicated by the sub-saturated temperature of the fluid at the exit. For 
this case, it is observed that nucleation initiates at the edges/corners close to the exit of the microchannel, as shown schematically in Fig. 3a. Even at a lower mass flux of $599 \mathrm{~kg} / \mathrm{m}^{2}$-s, the input heat is insufficient and the bubbles are unable to grow and depart from the edges. This results in coalescence of the bubbles and subsequently to the formation of large slugs at the location described earlier (Fig. 3b). These large slugs obstruct the flow and result in an increased pressure drop, as shown in Fig. 2. Further decrease in the flow rate, increases the rate of bubble nucleation. Now, as sufficient heat is available for the bubbles to grow, they expand laterally and occupy the entire microchannel width (Fig. 3c). However, due to the diverging cross-section the bubbles/ slugs do not get trapped inside the microchannel; rather depart rapidly with the flow.

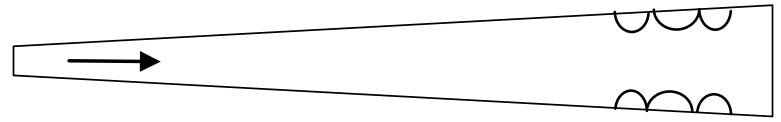

(a) $G=718 \mathrm{~kg} / \mathrm{m}^{2}-\mathrm{s}$

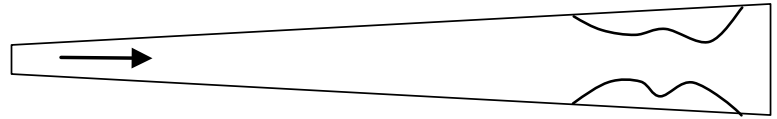

(b) $G=599 \mathrm{~kg} / \mathrm{m}^{2}-\mathrm{s}$

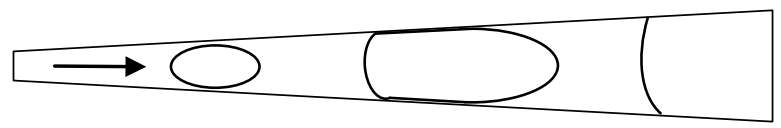

$$
\text { (c) } G=479-120 \mathrm{~kg} / \mathrm{m}^{2}-\mathrm{s}
$$

Fig. 3 Schematic representation of the observed flow boiling regimes at different flow rates through 4 deg microchannel. The flow is from left to right as indicated by the arrow. (Here ' $G$ ' denotes mass flux.)

This can explain the nature of the two phase curve as compared to the single phase curve in Fig. 2. In this figure, for flow rate less than $599 \mathrm{~kg} / \mathrm{m}^{2}-\mathrm{s}$, the pressure drop increases and reaches above the single phase curve. A comparison of pressure drop variation for two phase flow in diverging microchannel (Fig. 2) with that of uniform cross section microchannel presented by Singh et al. (2009c) suggest qualitative similarity between the two cases. However, the percentage deviation of pressure drop from the corresponding single phase curve is more in uniform cross section microchannel as compared to diverging microchannel.

Such type of variation in pressure drop with mass flux in conventional scale channels or macro-channels is also observed by various research groups, as reviewed in Kakac and Bon (2008). Based on the data available on boiling flow instabilities for conventional scale channels, they categorized the sudden increase in pressure drop and resulting instabilities into various types: Ledinegg type, density-wave type, pressure drop type, thermal oscillation and acoustic oscillation type instabilities. Inline with this, the extensive data on instabilities for diverging microchannel could be helpful to understand the physical phenomenon behind it. Therefore, in a succeeding section (Section 4), the effect of diverging angle on sudden increase in pressure drop is examined.

\subsection{Effect of Heat flux}

Figure 4 shows the variation of pressure drop with heat flux at a constant mass flux of $599 \mathrm{~kg} / \mathrm{m}^{2}$-s. The flow is in single phase between points ' $a$ ' and ' $b$ ' of the curve; about $12 \%$ reduction in pressure drop is observed in this region with respect to the no-heating case, due to reduction in viscosity because of heating. This region is followed by a sudden rise in pressure drop at $12 \mathrm{~W} / \mathrm{cm}^{2}$; simultaneous visualization of the flow suggests that the rise in pressure drop is due to accumulation of bubbles at nucleation sites before their departure. Therefore, region between ' $b$ ' to ' $c$ ' corresponds to subcooled nucleate boiling (see Fig. 3a). Again after $15 \mathrm{~W} / \mathrm{cm}^{2}$ (i.e. region from ' $c$ ' to ' $\mathrm{d}$ ') the pressure drop falls due to frequent formation and departure of bubbles from the nucleation sites. In this region, slug flow starts dominating from the inlet reservoir itself. Notice that the pressure drop in this region is smaller than the corresponding single phase pressure drop. This observation is of great practical significance as large pressure drop penalty is typically attributed as the reason for not employing two phase cooling in microchannel.

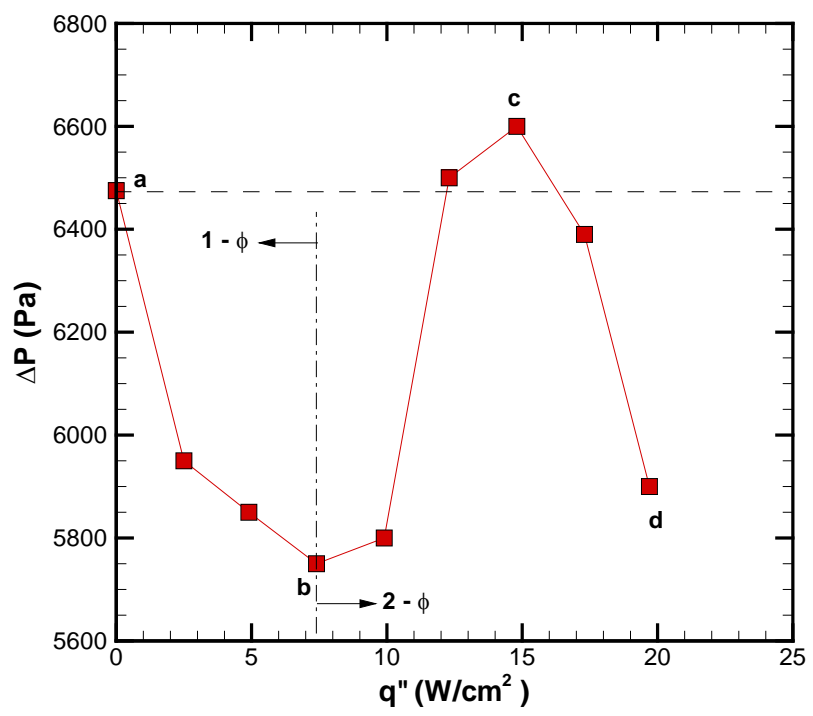

Fig. 4 Pressure drop variation inside 4 deg microchannel at constant mass flux of $599 \mathrm{~kg} / \mathrm{m}^{2}$-s and varying heat fluxes. The dotted horizontal line corresponds to no heating case.

Another interesting observation from Fig. 4 is that there are up to three points with the same pressure drop. For example, a horizontal line corresponding to $6200 \mathrm{~Pa}$ of pressure drop intersects the curve between 'a' and 'b'; 'b' and 'c'; 'c' and 'd'. Of these, the first point is in single phase whereas the other two points are in two phase. Such an observation was first reported by Singh et al. (2009c) with respect to boiling in a uniform cross section microchannel. The point with the maximum heat transfer coefficient or minimum surface temperature can be chosen as the operating point, wherever such flexibility exists.

\section{EFFECT OF DIVERGENCE ANGLE ON PRESSURE DROP}

The above mentioned measurements were repeated in microchannel of other divergence angles, with the objective of qualitatively checking the presented trends. The results also help to bring out the effect of divergence angle on the flow behavior. Experiments presented in this section were carried out on microchannels with divergence angle of 4 , 8 and 12 deg in the flow rate range of 0.1 to $1 \mathrm{ml} / \mathrm{min}\left(117-1197 \mathrm{~kg} / \mathrm{m}^{2}\right.$ $\mathrm{s}$ of mass flux at inlet) and at constant heat flux of $5.7 \mathrm{~W} / \mathrm{cm}^{2}$.

\subsection{Mean pressure}

Figure 5 shows pressure drop versus mass flux for the three microchannels for which data is available. The figure shows qualitatively similar trend of pressure drop for 8 and 12 deg microchannels as that of $4 \mathrm{deg}$. Note the single phase pressure drop is larger for the smaller angle microchannel, and this trend is generally applicable to the two phase flow regime as well. In a separate detailed 
study (Duryodhan et al., 2011) on single phase flow, we found that the overall pressure drop across the microchannel decreases with an increase in the divergence angle from $4 \mathrm{deg}$ to $12 \mathrm{deg}$, whereas it increases beyond it (i.e. for divergence angle of $16 \mathrm{deg}$ ). Separation of the flow at higher degree of divergence is the reason for the larger pressure drop in the largest divergence angle microchannel, which was further confirmed through numerical simulations. Therefore, critical angle for single phase flow through diverging microchannel is about 16 deg (in agreement with conventional result) beyond which pressure drop increases anomalously.

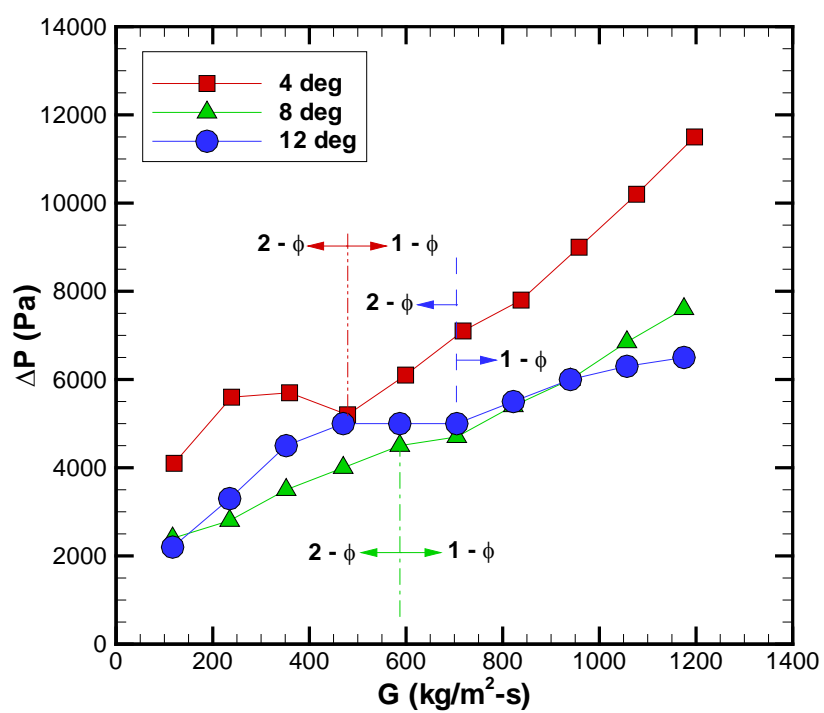

Fig. 5 Pressure drop variation with mass flux inside 4, 8 and 12 deg microchannel at $5.7 \mathrm{~W} / \mathrm{cm}^{2}$. $(1-\phi=$ Single phase regime, $2-\phi$ = Two phase regime.)

Figure 5 shows that there is a systematic shift in ONB point with divergence angle. For 8 deg microchannel, the pressure drop decreases below the 12 deg microchannel for flow rate less than $587 \mathrm{~kg} / \mathrm{m} 2$-s. Also, it is interesting to see from the figure that the slope of the sudden increase in mean pressure drop at the onset of boiling point reduces with an increase in divergence angle.

\subsection{Pressure and Temperature instabilities}

Figure 6 shows the pressure fluctuation with time through different divergence angle microchannels, at three different mass fluxes. The three mass fluxes are selected based on visual observation. It is observed that the pressure fluctuation is a function of both mass flux and divergence angle. Figure 6a describes the pressure instabilities for 4 deg microchannel at flow rates of $1,0.5$ and $0.1 \mathrm{ml} / \mathrm{min}(1197,599$ and $120 \mathrm{~kg} / \mathrm{m}^{2}-\mathrm{s}$ ). At $1197 \mathrm{~kg} / \mathrm{m}^{2}$-s, the flow remains in single phase; the pressure instabilities are therefore negligibly small at this flow rate. At $599 \mathrm{~kg} / \mathrm{m}^{2}-\mathrm{s}$, the flow is again in single phase with slight increase in pressure instabilities; see Fig. 6a. At $120 \mathrm{~kg} / \mathrm{m}^{2}-\mathrm{s}$, the flow is in two phases with large pressure instabilities (up to $\pm 1000 \mathrm{~Pa}$ ); see figure 6a. The instability at this mass flux is the combine effect of slug formation and their delay in departure.

Comparison of Figs. 6a, 6b, 6c show that the frequency of pressure fluctuation is more for 12 deg microchannel (Fig. 6c) as compared to 4 deg (Fig. 6a) and 8 deg (Fig. 6b) microchannels at a specified mass fluxes. The amplitude of fluctuation also depends on the divergence angle.

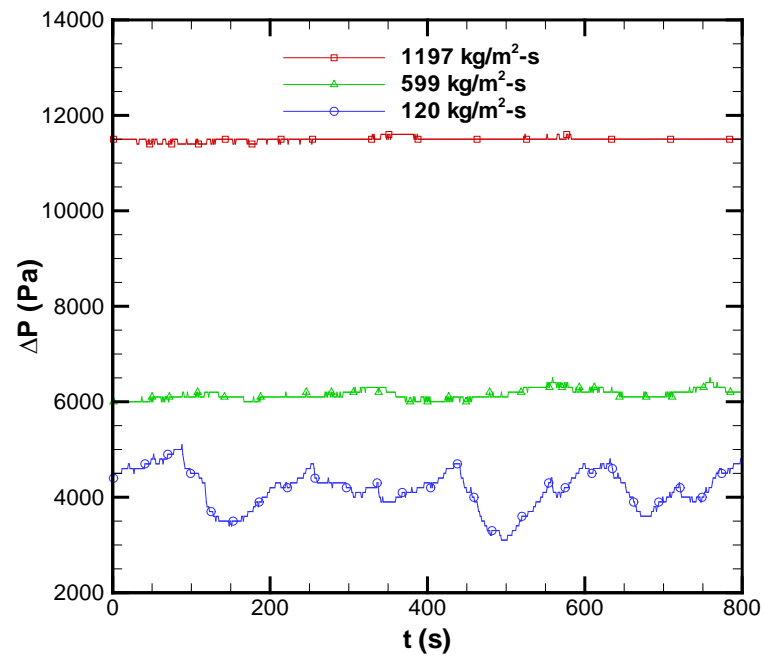

(a)

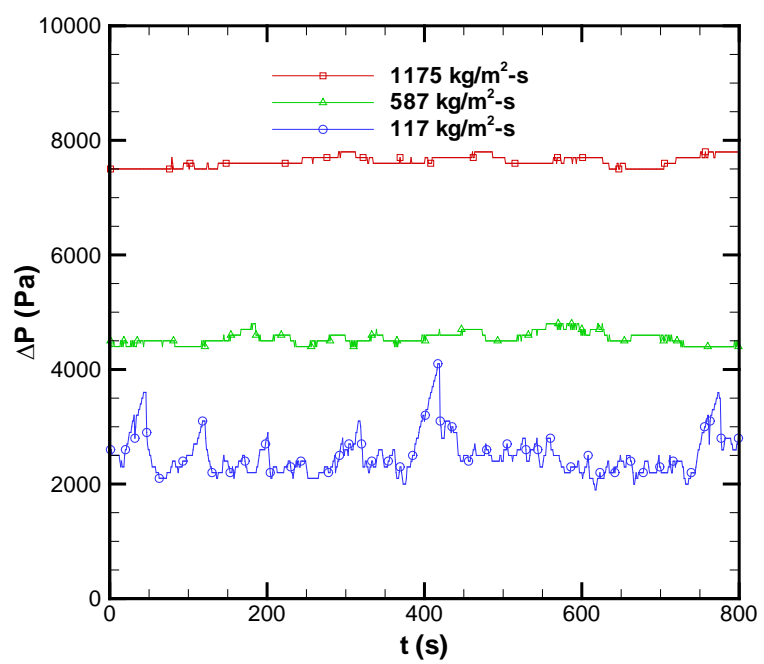

(b)

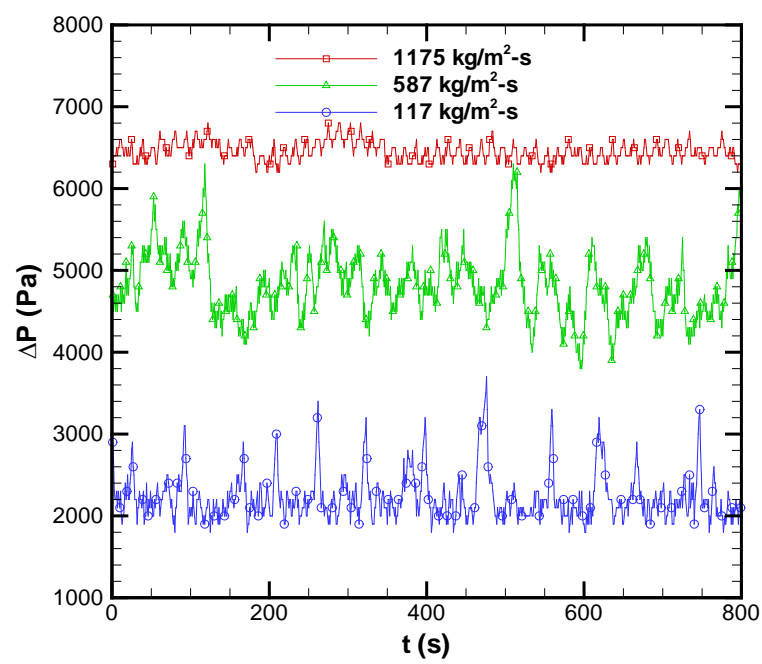

(c)

Fig. 6 Pressure instability plot at different mass fluxes for (a) 4 deg, (b) $8 \mathrm{deg}$, (c) $12 \mathrm{deg}$ microchannel at heat flux of $5.7 \mathrm{~W} / \mathrm{cm}^{2}$. 
Figure 7 shows the temperature instability plot as a function of divergence angle. This instability is taken from the inlet temperature sensor with mass flow rate of $0.4 \mathrm{ml} / \mathrm{min}\left(479 \mathrm{~kg} / \mathrm{m}^{2}-\mathrm{s}\right)$ and heat flux of $5.7 \mathrm{~W} / \mathrm{cm}^{2}$. It shows that the amplitude of temperature instability increases from 4 deg to 8 deg microchannels, and increases further for 12 deg microchannel. This observation is in line with the corresponding observation for pressure instability, as explained with respect to Fig. 6. Surprisingly, the instability appears more periodic for $12 \mathrm{deg}$ microchannel. This graph also shows that the average inlet temperature for 12 deg is more as compared to the 8 deg and 4 deg microchannels.

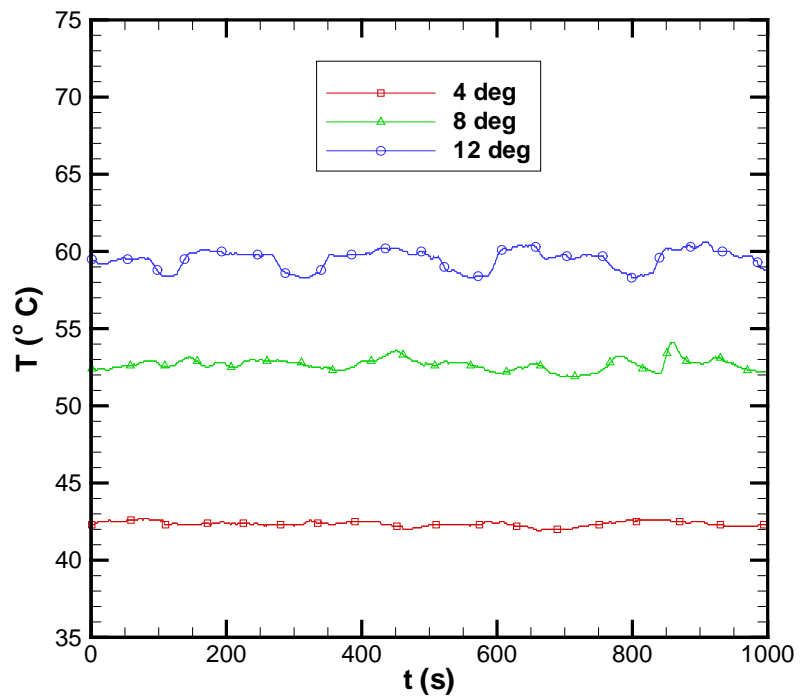

Fig. 7 Temperature instability plot at the inlet of diverging microchannel with different divergence angle at $0.4 \mathrm{ml} / \mathrm{min}$ (479 $\mathrm{kg} / \mathrm{m}^{2}-\mathrm{s}$ ) and $5.7 \mathrm{~W} / \mathrm{cm}^{2}$.

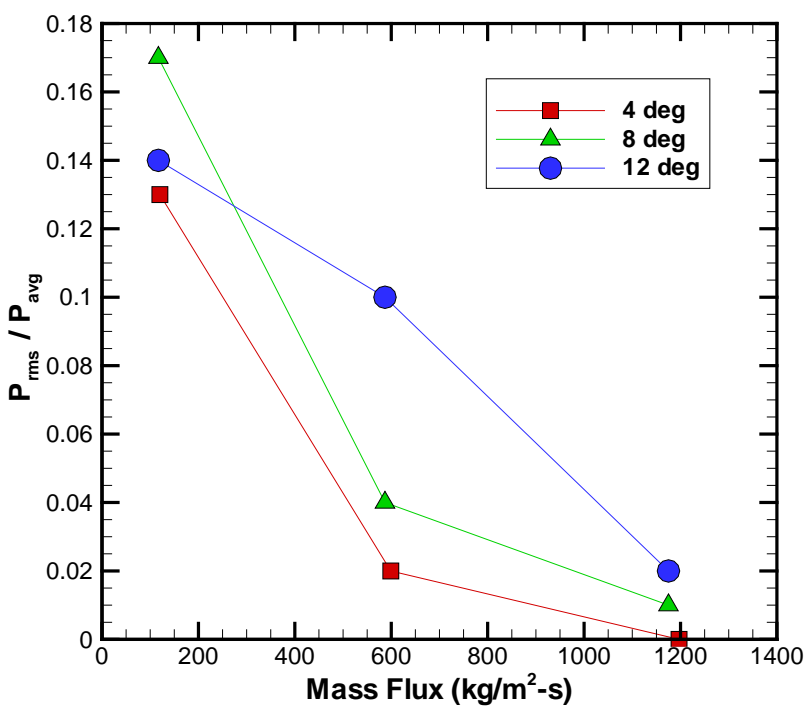

Fig. 8 Variation of $\mathrm{P}_{\mathrm{rms}} / \mathrm{P}_{\mathrm{avg}}$ with mass flow rate for diverging microchannel with different angle of divergence at heat flux of $5.7 \mathrm{~W} / \mathrm{cm}^{2}$.

In an effort to study the effect of divergence angle on pressure instability, normalized pressure rms $\left(P_{\mathrm{rms}} / P_{\text {avg }}\right)$ is plotted in Fig. 8, as a function of mass flux at heat flux of $5.7 \mathrm{~W} / \mathrm{cm}^{2}$. The figure shows a systematic reduction in normalized pressure rms with mass flux and divergence angle. The ratio of rms pressure with respect to the corresponding average pressure is more for $12 \mathrm{deg}$ microchannel as compared to 4 and 8 deg microchannels. But for mass flux $117 \mathrm{~kg} / \mathrm{m}^{2}$-s (i.e. at the lowest flow rate studied in the present work), it drops down to below the corresponding value for $8 \mathrm{deg}$. The reason for slope change at mass flux lower than $600 \mathrm{~kg} / \mathrm{m}^{2}$-s is because of the transition phase between nucleate and slugs boiling which is the result of low heat flux of $5.7 \mathrm{~W} / \mathrm{cm}^{2}$.

\section{CONCLUSIONS}

This work experimentally investigates the effect of mass flux, heat flux and divergence angle on pressure drop during boiling flow in diverging microchannels. As expected, it was observed that the pressure drop varies non-linearly with mass flux in single phase heating as well as in two phase boiling regimes. The slope of demand curve due to sudden increase in mean pressure drop at the point of onset of boiling is observed to be an inverse function of divergence angle of microchannel. It is observed that at this point the mean pressure drop rises in $4 \mathrm{deg}$, drops in 8 deg, whereas remains same for 12 deg microchannel. Therefore, similar to single phase flow through diverging microchannel, existence of critical angle of divergence in order to reduce the mean pressure drop rise at the point of onset of boiling seems to exist. Also, study of pressure and temperature fluctuations with time provide preliminary information regarding the role of divergence angle in reducing the flow instabilities. Our preliminary study suggests that diverging microchannel can reduce the flow instabilities. These results suggest that diverging microchannels can be fruitfully employed in design of future micro heat sinks.

\section{NOMENCLATURE}

$\begin{array}{ll}\mathrm{W}_{\mathrm{t}(\mathrm{i})} & \text { inlet top width }(\mu \mathrm{m}) \\ \mathrm{W}_{\mathrm{t}(\mathrm{o})} & \text { outlet top width }(\mu \mathrm{m}) \\ \mathrm{H} & \text { height }(\mu \mathrm{m}) \\ \mathrm{L} & \text { length }(\mathrm{mm}) \\ \theta & \text { divergence Angle }\left(^{\circ}\right) \\ \mathrm{D}_{\mathrm{h}} & \text { hydraulic Diameter }(\mu \mathrm{m}) \\ \mathrm{P} & \text { pressure }(\mathrm{Pa}) \\ \Delta \mathrm{P} & \text { pressure drop }(\mathrm{Pa}) \\ \bullet & \\ m & \text { volume flow rate }(\mathrm{ml} / \mathrm{min}) \\ \mathrm{T} & \text { temperature }\left({ }^{\circ} \mathrm{C}\right) \\ \mathrm{t} & \text { time }(\mathrm{s}) \\ \mathrm{G} & \text { mass flux }\left(\mathrm{kg} / \mathrm{m}^{2}-\mathrm{s}\right) \\ \mathrm{q} & \text { heat flux }\left(\mathrm{W} / \mathrm{cm}^{2}\right) \\ & \\ \text { Subscripts } \\ \text { avg } & \text { average } \\ \mathrm{rms} & \text { root mean square }\end{array}$

\section{REFERENCES}

Agrawal, A., and Singh, S.G., 2011, "A review of state-of-the-art on flow boiling of water in microchannel," International Journal of Microscale and Nanoscale Thermal and Fluid Transport Phenomena, Vol. 2, pp. 1-39.

https://www.novapublishers.com/catalog/product_info.php?products_id $\underline{=21781}$

Bergles, A. E., and Kandlikar, S. G., 2005, "On the nature of critical heat flux in microchannels,” Journal of Heat Transfer, 127(10), 101 107.

http://dx.doi.org/10.1115/1.1839587

Bhide, R.R., Singh, S.G., Sridharan, A., and Agrawal, A., 2011, "An 
active control strategy for reduction of pressure instabilities during flow boiling microchannel," Journal of Micromechanics and Microengineering, Vol. 21, 035021. http://dx.doi.org/10.1088/0960-1317/21/3/035021

Duryodhan, V. S., Singh, S. G., Agrawal, A., 2011, "Liquid flow through diverging microchannel," Journal of Fluid Mechanics, under review.

Kakac, S., Bon, B., 2008, "A Review of two-phase flow dynamic instabilities in tube boiling systems," International Journal of Heat and Mass Transfer, 51, 399 - 433.

http://dx.doi.org/10.1016/j.ijheatmasstransfer.2007.09.026

Kandlikar, S.G., 2002, "Fundamental issues related to flow boiling in minichannels and microchannels," Experimental Thermal and Fluid Science, 26, 389-407.

http://dx.doi.org/10.1016/S0894-1777(02)00150-4

Kandlikar, S.G., 2006, "Nucleation characteristic and stability considerations during flow boiling in microchannels"; Experimental Thermal and Fluid Science, 30, 441 - 447.

http://dx.doi.org/10.1016/j.expthermflusci.2005.10.001

Kandlikar, S.G., Balasubramanian, P., 2005, "Effect of gravitational orientation on flow boiling of water in 1054 x 197 micron parallel minichannels," ASME Paper No. ICMM 2004-2379, in: Second International Conference on Microchannels and Minichannels, Rochester, NY, USA, 17-19 June 2004, Journal of Heat Transfer 127, pp. 539-550.

http://dx.doi.org/10.1115/ICMM2004-2379

Kennedy, J.E., Roach, G.M., Dowling, M.F., Abdel-Khalik S.I., Ghiaasiaan, S.M., Jeter, S.M., 2000, "The Onset of Flow Instability in Uniformly Heated Horizontal Microchannels," Journal of Heat Transfer, 122, 118-25.

http://dx.doi.org/10.1115/1.521442

Kuo, C.J., and Peles, Y., 2008, "Flow boiling instabilities in microchannels and means for mitigation by reentrant cavities,” Journal of Heat Transfer ASME, 1301-10.

http://dx.doi.org/10.1115/1.2908431

Lee, P.C. and Pan, C., 2008, "Boiling heat transfer and two phase flow of water in a single shallow microchannel with a uniform or diverging cross section,” Journal of Micromechanics and Microengineering, 13, 18.

http://dx.doi.org/10.1088/0960-1317/13/1/303

Lee, P.C., Tseng, F.G., and Pan, C., 2004, "Bubble dynamics in microchannels: Part I. Single microchannel,” International Journal of Heat and Mass Transfer, 47, 5575-89.

http://dx.doi.org/10.1016/j.ijheatmasstransfer.2004.02.031

Li, H.Y., Tseng, F.G., and Pan, C., 2004, "Bubble dynamics in microchannels: Part II. Two parallel microchannels,” International Journal of Heat and Mass Transfer, 47, 5591-601.

http://dx.doi.org/10.1016/j.ijheatmasstransfer.2004.02.032

Morini, G. L., 2004, "Laminar liquid flow through Silicon Microchannels,” Journal of Fluids Engineering 126, 485 - 489. http://dx.doi.org/10.1115/1.1760545
Park, J. E., Thome, J. R., Michel, B., 2009, "Effect of inlet orifice on saturated CHF and flow visualization in Multi-microchannel heat sinks," 25th IEEE SEMI-THERM Symposium. http://dx.doi.org/10.1109/STHERM.2009.4810735

Qu, W. and Mudawar I, 2003, "Measurement and prediction of pressure drop in two-phase micro-channel heat sinks," International Journal of Heat and Mass Transfer, 46 2737-53. http://dx.doi.org/10.1016/S0017-9310(03)00044-9

Qu, W., and Mudawar, I., 2004, "Measurement and Correlation of Critical Heat Flux in Two-Phase Micro-Channel Hat Sinks," International Journal of Heat and Mass Transfer, 47, pp. 2045-2059. http://dx.doi.org/10.1016/j.ijheatmasstransfer.2003.12.006

Singh S.G., Kulkarni A, Duttagupta S.P., Puranik B.P. Agrawal A, 2008, "Impact of aspect ratio on flow boiling of water in rectangular microchannels," Experimental Thermal and Fluid Science, 33, 153-160. http://dx.doi.org/10.1016/j.expthermflusci.2008.07.014

Singh, S.G., Agrawal, A., and Duttagupta, S.P., 2011, "Reliable MOSFET operation using two-phase microfluidics in presence of high heat flux transients," Journal of Micromechanics and Microengineering, Vol. 21, 105002.

http://dx.doi.org/10.1088/0960-1317/21/10/105002

Singh, S.G., Duttagupta, S.P., and Agrawal, A., 2009a, "In-situ impact analysis of very high heat flux transients on non-linear p-n diode characteristics and mitigation using on-chip single-phase and two-phase microfluidics," Journal of Microelectromechanical Systems, Vol. 18(6), pp. 1208-1219.

http://dx.doi.org/10.1109/JMEMS.2009.2035371

Singh, S.G., Jain, A., Sridharan, A., Duttagupta, S.P., and Agrawal, A., 2009b, "Flow map and measurement of void fraction and heat transfer coefficient using image analysis technique for flow boiling of water in silicon microchannel," Journal of Micromechanics and Microengineering, Vol. 19 (075004), pp. 1-9. http://dx.doi.org/10.1088/0960-1317/19/7/075004

Singh, S.G., Bhide, R.R., Duttagupta, S.P., Puranik, B.P., and Agrawal, A., 2009c, "Two-phase flow pressure drop characteristics in trapezoidal silicon microchannels," IEEE Transactions on Components and Packaging Technologies, Vol. 32 (4), pp. 887-900. http://dx.doi.org/10.1109/TCAPT.2009.2019634

Wang, G., Cheng, P., Bergles, A.E., 2008, "Effects of inlet/outlet configurations on flow boiling instability in parallel microchannels," International Journal of Heat and Mass Transfer, 51, 2267 - 2281. http://dx.doi.org/10.1016/j.ijheatmasstransfer.2007.08.027

Wu, H.Y., and Cheng, 2006, "Pressure drop and flow boiling instabilities in silicon microchannel heat sinks, Journal of Micromechanics and Microengineering,” 16, 2138 - 2146.

http://dx.doi.org/10.1088/0960-1317/16/10/030

Yen, T., Shoji, M., Takemura, F., Suzuki, Y., Kasagi N., 2006, "Visualisation of Convective Boiling Heat transfer in single microchannel with different shaped cross-section,” International Journal of Heat and Mass Transfer, 49, 3884 - 3894.

http://dx.doi.org/10.1016/j.ijheatmasstransfer.2005.12.024 